\title{
KHẢO SÁT THỤ̉C TRẠNG LỤ๋A CHỌN PHÁC ĐỒ HẠ GLUCOSE MÁU Ở CÁC BỆNH NHÂN ĐTĐ TÍP 2 MỚI PHÁT HIỆN TẠI BỆNH VIỆN NỘI TIẾT TRUNG ƯƠNG Hoàng Thu Trang ${ }^{1}$, Lê Quang Toàn ${ }^{1}$, Nguyễn Khoa Diệu Vân ${ }^{2}$ 1. Bệnh viện Nội tiết Trung ương; 2. Đại học Y Hà Nội
}

DOI: $10.47122 / v j d e .2020 .45 .2$

\section{TÓM TẮT}

Mục tiêu: Khảo sát thực trạng lựa chọn thuốc hạ glucose máu ở các bệnh nhân ĐTĐ típ 2 mới phát hiện tại Bệnh viện Nội Tiết Trung ương. Đối tượng và phuơng pháp: Đối tượng nghiên cứu gồm 204 bệnh nhân tuổi từ 16-81 mới được chẩn đoán xác định bệnh ĐTĐ típ 2 đến khám tại Bệnh viện Nội tiết Trung ương. Kết quả: Metformin được chỉ định ở $85 \%$ bệnh nhân dùng đơn trị thuốc uống hạ glucose máu. Các kết hợp thuốc uống thường dùng nhất là metformin phối hợp với ức chế DPP4 và với ức chế SGLT2, chiếm lần lượt $41,9 \%$ và $22,6 \%$ trong các phác đồ kết hợp thuốc uống. Trong các phác đồ có insulin, insulin đơn trị và kết hợp metformin chiếu hầu hết các trường hợp, lần lượt $62,5 \%$ và $21,3 \%$. Ở bệnh nhân có HbA1c < 7\%, 88,5\% được dùng đơn trị thuốc uống; với mức $\mathrm{HbA1c} 7$ $<8,5 \%$ : $62 \%$ dùng kết hợp thuốc uống và $32 \%$ dùng thuốc uống đơn trị; với mức $\mathrm{HbA} 1 \mathrm{c} 8,5$ $<10 \%$ : 65,5\% dùng thuốc uống kết hợp, $31 \%$ có dùng insulin; với mức $\mathrm{HbA} 1 \mathrm{c} \geq 10 \%$ : $66,5 \%$ có dùng insulin, $32,5 \%$ dùng thuốc uống kết hợp. Kết luận: Ở bệnh nhân ĐTĐ típ 2 mới được chẩn đoán tại Bệnh viện Nội tiết Trung ương, metformin là thuốc được sử dụng ở hầu hết bệnh nhân, cả đơn trị và kết hợp. Các thuốc uống hạ glucose máu thế hệ mới cũng được sử dụng ở môt tỷ lệ đáng kể bệnh nhân, nhiều hơn so với sulfonylurea. Phần lớn chỉ định các phác đồ thuốc hạ glucose máu tuân theo các khuyến cáo chung hiện nay. Tuy nhiên, có tình trạng điều trị kiểm soát glucose máu tích cực hơn ở bệnh nhân có tình trạng gluose máu tăng mức nhẹ đến trung bình và ngược lại có tình trạng điều trị thiếu tích cực ở bệnh nhân có tình trạng glucose máu rất cao. tip 2.

\author{
ABSTRACT \\ Survey on the choices of hypolycemic \\ drugs for patients with newly diagnosed \\ type 2 diabetes at the National Hospital \\ of Endocrinology \\ Hoang Thu Trang ${ }^{1}$, Le Quang Toan ${ }^{1}$, \\ Nguyen Khoa Dieu Van ${ }^{2}$ \\ 1. National Hospital of Endocrinology; \\ 2. Ha Noi Medical University
}

Objectives: To investigate the choices hypoglycemic drugs for patients with newly diagnosed type 2 diabetes at the National Hospital of Endocrinology. Subjects and methods: The study included 204 patients aged 16 to 81 with newly diagnosed with type 2 diabetes and were prescribed with hypoglycemic drugs. Results: Metformin was prescribed in $85 \%$ of patients as oral monotherapy. The most common oral drug combinations were metformin with DPP4 inhibitors or SGLT2 inhibitors, accounting of $41.9 \%$ and $22.6 \%$, respectively. Among the patients using insulin, insulin monotherapy and its combination with metformin were prescribed in most patients, accounting for $62.5 \%$ và $21.3 \%$, respectively. In patients with $\mathrm{HbAlc}<7 \%, 88,5 \%$ received prescribed oral monotherapy; with HbA1c 7 - <8.5\%: $62 \%$ and $32 \%$ received oral drug combination and monotherapy, respectively; with HbA1c 8.5 $<10 \%$ : $65.5 \%$ received oral drug combination and $31 \%$ used insulin; with HbA1c $\geq 10 \%$ : $66.5 \%$ and $32.5 \%$ used insulin and oral drug combinations, respectively. Conclusions: In patients with newly diagnosed type 2 diabetes, metformin was used by most patients as monotherapy or in combination with other drugs. New oral hypoglycemic drugs were prescribed for a significant proportion of the 
patients. Most hypoglycemic drug choices followed present recommendations. However, there was some overuse of hypoglycemic drugs in patients with slightly to moderately elevated $\mathrm{HbAlc}$, and in contrary some underuse in patients with very high $\mathrm{HbAlc}$.

Keywords: Choices of hypoglucemic drugs, type 2 diabetes.

Chịu trách nhiệm chính: Hoàng Thu Trang

Ngày nhận bài: $5 / 1 / 2021$

Ngày phản biện khoa học: 11/1/2021

Ngày duyệt bài: 4/3/2021

Email:dtnckhbvnt@gmail.com

\section{1. ĐẶT VẤN ĐỀ}

Đái tháo đường (ĐTĐ), chủ yếu là ĐTĐ típ 2 , đang trở thành bệnh dịch nguy hiểm trên toàn cầu do sự gia tăng nhanh chóng số người mắc, nhiều biến chứng ảnh hưởng nghiêm trọng đến sức khỏe và tuổi thọ, chi phí tốn kém, là gánh nặng cho bản thân người bệnh, gia đình họ và toàn xã hội. Hiện nay theo WHO trên thế giới có khoảng 425 triệu dân số mắc bệnh ĐTĐ tương đương khoảng $8,5 \%$ dân số. Ở Việt Nam, tỉ lệ mắc ĐTĐ khoảng $8 \%$, trong đó chủ yếu là ĐTĐ típ 2 , vậy nên việc điều trị và quản lý bệnh tốt là hết sức cần thiết.

Kiểm soát glucose máu (GM) là một trong các mục tiêu chính trong điều trị ĐTĐ. Bên cạnh chế độ ăn và luyện tập, hầu hết mọi bệnh nhân ĐTĐ típ 2 đều cần được điều trị bằng thuốc hạ GM. Ở bệnh nhân mới được chẩn đoán ĐTĐ típ 2, việc lựa chọn phác đồ hạ GM phù hợp với tình trạng $\mathrm{GM}$ của bệnh nhân là rất quan trọng, vừa giúp kiểm soát $\mathrm{GM}$ nhanh, hiệu quả, đông thời tránh được tác dụng phụ nguy hiểm là hạ GM. Mặt khác hiện nay, bên cạnh các thuốc hạ GM kinh điển ngày càng có nhiều loại thuốc điều trị ĐTĐ típ 2 được đưa vào sử dụng. Đồng thời các hướng dẫn điều trị cũng liên tục đưa ra các khuyến cáo mới về sử dụng thuốc hạ GM trong ĐTĐ típ 2 dựa trên các căn cứ khác nhau, trong đó có tình trạng GM. Bệnh viện Nội tiết Trung ương, là trung tâm điều trị và theo dõi cho hơn 20.000 bệnh nhân ĐTĐ mỗi năm, quản lý số lượng bệnh nhân mắc ĐTĐ lớn nhất cả nước. Tuy vậy, việc khảo sát sự lựa chọn phác đồ hạ GM cho bệnh nhân mắc ĐTĐ típ 2 mới chẩn đoán chưa được thực hiện. Nghiên cứu về vấn đề này sẽ cung cấp thông tin để giúp khắc phục những sự bất hợp lý trong lựa chọn phác đồ hạ GM cho các đối tượng bệnh nhân này.

Vì vậy, chúng tôi tiến hành nghiên cứu này với mục tiêu: Khảo sát thực trạng và một số yếu tố liên quan tới việc lựa chọn phác đồ hạ Glucose máu ở các bệnh nhân ĐTĐ typ 2 mới phát hiện tại Bệnh viện Nội tiết Trung wơng.

\section{2. ĐỐI TƯợNG VÀ PHƯƠNG PHÁP NGHIÊN CÚU}

\section{1. Đối tượng nghiên cứu:}

- Gồm 204 bệnh nhân được lựa chọn theo tiêu chuẩn:

Được chẩn đoán xác định bệnh ĐTĐ típ 2 lần đầu, đến khám tại Bệnh viện Nội tiết Trung ương trong thời gian từ 10/2019 đến $09 / 2020$ và được bác sỹ chỉ định sử dụng phác đồ hạ glucose máu. Chẩn đoán ĐTĐ típ 2 theo các tiêu chuẩn của Hội ĐTĐ Mỹ năm 2019[1].

- Loại trừ những bệnh nhân đang mắc các bệnh cấp tính khác, bệnh nhân không đồng ý tham gia nghiên cứu.

\subsection{Phương pháp nghiên cứu}

- Nghiên cứu quan sát cứu mô tả cắt ngang bằng các phương pháp:

- Hỏi bệnh và thu thập qua hồ sơ những bệnh nhân thỏa mãn tiêu chuẩn lựa chọn của nghiên cứu, sau đó thu thập các thông tin liên quan đến nội dung nghiên cứu bao gồm các đặc điểm lâm sàng (triệu chứng lâm sàng của tăng glucose máu, BMI, huyết áp); cận lâm sàng (glucose huyết tương tĩnh mạch (GHTTM) lúc đói, HbA1c; các chỉ số lipid máu), các biến chứng của bệnh ĐTĐ. Có mắc các bệnh đồng mắc hay gặp như tăng huyết áp[2] và rối loạn chuyển hóa lipid[3] theo khuyến cáo của hội Tim Mạch Việt Nam

- Các thông tin của bệnh nhân được thu thập vào mẫu bệnh án nghiên cứu thống nhất.

\subsection{Xử lý số liệu}

Tất cả bệnh án nghiên cứu được kiểm tra, các số liệu sẽ được mã hóa và nhập bằng phần mềm Epidata 3.1. Xử lý và phân tích số liệu bằng phần mềm thống kê SPSS 16.0. theo các thuật toán thống kê sử dụng trong y học. 


\section{4. Đạo đức trong nghiên cứu}

Thông tin của bệnh nhân được đảm bảo giữ bí mật và chỉ phục vụ cho mục tiêu nghiên cứu.

\section{KẾT QUẢ NGHIÊN CÚU}

\section{1. Đặc điểm của bệnh nhân nghiên cứu}

Bảng 3.1. Phân bố nhóm tuổi và tuổi trung bình theo giới tính

\begin{tabular}{|l|c|c|c|}
\hline Tuổi & $\begin{array}{c}\text { Nam } \\
(\mathbf{n = 1 1 8})\end{array}$ & $\begin{array}{c}\text { Nữ } \\
(\mathbf{n = 8 6})\end{array}$ & $\begin{array}{c}\text { Tổng } \\
(\mathbf{N = 2 0 4})\end{array}$ \\
\hline$<30$ & $5(4,2 \%)$ & $1(1,2 \%)$ & $6(2,9 \%)$ \\
\hline $30-39$ & $15(12,7 \%)$ & $13(15,1 \%)$ & $28(13,7 \%)$ \\
\hline $40-49$ & $37(31,4 \%)$ & $17(19,8 \%)$ & $54(26,5 \%)$ \\
\hline $50-59$ & $32(27,1 \%)$ & $29(33,7 \%)$ & $61(29,9 \%)$ \\
\hline$\geq 60$ & $29(24,6 \%)$ & $26(30,2 \%)$ & $55(27,0 \%)$ \\
\hline Tổng & $118(100,0 \%)$ & $86(100,0 \%)$ & $204(100,0 \%)$ \\
\hline Trung bình \pm ĐLC & $50,9 \pm 12,3$ & $52,9 \pm 10,8$ & $51,7 \pm 11,7$ \\
\hline Thấp nhất & 18 & 29 & 16 \\
\hline Cao nhất & 81 & 74 & 81 \\
\hline
\end{tabular}

Nhận xét: Tổng số có 204 bệnh nhân, bao gồm 118 năm và 86 nữ được đưa vào nghiên cứu. Tuổi trung bình của bệnh nhân nghiên cứu là $51,7 \pm 11,7$ tuổi, thấp nhất là 16 tuổi, cao nhất là 81 tuổi. Phần lớn bệnh nhân nghiên cứu từ 40 tuổi trở lên (170 bệnh nhân chiếm $83,4 \%)$. Tuổi trung bình của nam $(50,9 \pm 12,3)$ thấp hơn nữ $(52,9 \pm 10,8)$.

Bảng 3.2. Các bệnh lý đồng mắc liên quan đến ĐTĐ

\begin{tabular}{|c|c|c|c|c|c|c|c|}
\hline \multirow{2}{*}{ Bệnh đồng mắc } & \multicolumn{2}{|c|}{$\begin{array}{c}\text { Nam } \\
(\mathbf{n = 1 1 8})\end{array}$} & \multicolumn{2}{c|}{$\begin{array}{c}\text { Nũ̃ } \\
(\mathbf{n}=\mathbf{8 6})\end{array}$} & \multicolumn{2}{c|}{$\begin{array}{c}\text { Tổng } \\
(\mathbf{N = 2 0 4 )}\end{array}$} & \multirow{2}{*}{$\mathbf{p}$} \\
\cline { 2 - 8 } & SL & TL & SL & TL & SL & TL & \\
\hline Tăng huyết áp & 24 & $20,3 \%$ & 30 & $34,9 \%$ & 45 & $26,5 \%$ & 0,006 \\
\hline Rối loạn lipid máu & 54 & $45,8 \%$ & 42 & $48,8 \%$ & 96 & $47,1 \%$ & 0,673 \\
\hline
\end{tabular}

Nhận xét: Tăng huyết áp gặp ở $26,5 \%$ và rối loạn lipid máu gặp ở $47,1 \%$, trong đó nữ có tỷ lệ tăng huyết áp cao hơn nam có ý nghĩa thống kê; không có khác biệt về tỷ lệ rối loạn lipid máu giữa 2 giới.

Bảng 3.3. Các đặc điểm lâm sàng của bệnh nhân nghiên cứu

\begin{tabular}{|l|l|c|}
\hline \multicolumn{2}{|l|}{ Đặc điểm } & Giá trị \\
\hline \multirow{3}{*}{ Triệu chứng tăng GM } & Có [n(\%)] & $98(48,0 \%)$ \\
\cline { 2 - 3 } & Không [n(\%)] & $106(52,0 \%)$ \\
\hline & Thấp nhất & 12,43 \\
\cline { 2 - 3 } & Cao nhất & 34,96 \\
\cline { 2 - 3 } BMI $\left(\mathrm{kg} / \mathrm{m}^{2}\right)$ & Trung bình \pm ĐLC & $23,22 \pm 2,89$ \\
\cline { 2 - 3 } & $<18,5[\mathrm{n}(\%)]$ & $8(3,9 \%)$ \\
\cline { 2 - 3 } & $18,5-22,9[\mathrm{n}(\%)]$ & $91(44,6 \%)$ \\
\cline { 2 - 3 } & $23,0-24,9[\mathrm{n}(\%)]$ & $59(28,9 \%)$ \\
\cline { 2 - 3 } & $\geq 25,0[\mathrm{n}(\%)]$ & $46(22,5 \%)$ \\
\hline
\end{tabular}

Nhận xét: Gần một nửa bệnh nhân có các triệu chứng của tăng glucose máu. BMI trung bình tại thời điểm phát hiện ĐTĐ là $23,22 \pm 2,89 \mathrm{~kg} / \mathrm{m}^{2}$, với trên một nửa bệnh nhân có $\mathrm{BMI} \geq 23$ $\mathrm{kg} / \mathrm{m}^{2}$, chiếm $51,4 \%$. 
Bảng 3.4. Glucose huyết tương tĩnh mạch (GHHTM) lúc đói và HbAlc

\begin{tabular}{|l|c|l|c|}
\hline GHTTM lúc đói (mmol/L) & Giá trị & \multicolumn{1}{|c|}{ HbA1c $(\%)$} & Giá trị \\
\hline Thấp nhất & 4,7 & Thấp nhất & $5,4 \%$ \\
\hline Cao nhất & 26,09 & Cao nhất & $16,7 \%$ \\
\hline Trung bình \pm ĐLC & $11,42 \pm 4,8$ & Trung bình \pm ĐLC & $9,3 \pm 2,5 \%$ \\
\hline$<7,0[\mathrm{n}(\%)]$ & $31(15,2 \%)$ & $<7,0[\mathrm{n}(\%)]$ & $43(21,1 \%)$ \\
\hline $7,0-10,0[\mathrm{n}(\%)]$ & $75(36,8 \%)$ & $7,0-<8,5[\mathrm{n}(\%)]$ & $54(26,5 \%)$ \\
\hline$>10,0-<16,7[\mathrm{n}(\%)]$ & $66(32,4 \%)$ & $8,5-<10[\mathrm{n}(\%)]$ & $29(14,2 \%)$ \\
\hline$\geq 16,7[\mathrm{n}(\%)]$ & $32(15,7 \%)$ & $\geq 10,0[\mathrm{n}(\%)]$ & $78(38,2 \%)$ \\
\hline
\end{tabular}

Nhận xét: GHTTM lúc đói trung bình lúc phát hiện ĐTĐ là $11,42 \pm 4,8 \mathrm{mmol} / \mathrm{L}$, giá trị thấp nhất là $4,7 \mathrm{mmol} / \mathrm{L}$, cao nhất là $26,09 \mathrm{mmol} / \mathrm{L}$. 36,8\% bệnh nhân có GHTTM lúc đói từ $7-10$ $\mathrm{mmol} / \mathrm{L}, 48,1 \%$ bệnh nhân có giá trị $>10 \mathrm{mmol} / \mathrm{L}$ và $15,7 \%$ có giá trị $>16,7 \mathrm{mmol} / \mathrm{L}$.

HbA1c lúc mới chẩn đoán ĐTĐ dao động từ 5,4\% - 16,7\% với giá trị trung bình là $9,3 \pm 2,5 \%$, trong đó có bệnh nhân có mức $>10 \%$ chiếm tỷ lệ cao nhất là $38,2 \%$, tiếp theo là mức $7,0-<8,5 \%$ chiếm $26,5 \%$; thấp nhất là mức $8,5-<10 \%$ chiếm $14,2 \%$.

\subsection{Lựa chọn thuốc hạ glucose máu cho bệnh nhân}

Bảng 3.5. Các phác đồ (PĐ) theo số lượng thuốc hạ glucose máu

\begin{tabular}{|l|c|c|c|c|c|}
\hline & $\begin{array}{c}\text { Không } \\
\text { dùng thuốc }\end{array}$ & $\begin{array}{c}\text { PĐ 1 } \\
\text { thuốc }\end{array}$ & $\begin{array}{c}\text { PĐ 2 } \\
\text { thuốc }\end{array}$ & $\begin{array}{c}\text { PĐ 3 } \\
\text { thuốc }\end{array}$ & $\begin{array}{c}\text { PĐ 4 } \\
\text { thuốc }\end{array}$ \\
\hline Số BN & 22 & 90 & 65 & 24 & 3 \\
\hline Tỷ lệ trong toàn bộ BN (\%) & 10,8 & 44,1 & 31,9 & 11,8 & 1,4 \\
\hline Tỷ lệ trong BN dùng thuốc (\%) & & 49,5 & 35,7 & 13,2 & 1,6 \\
\hline
\end{tabular}

Nhận xét: Tỷ lệ bệnh nhân được điều trị thuốc hạ glucose máu là $89,2 \%$. Tỷ lệ giảm dần khi số lượng thuốc tăng lên. Trong số bệnh nhân có dùng thuốc hạ glucose máu, phác đồ 1 thuốc là cao nhất chiếm $49,5 \%$, tiếp lần lượt là phác đồ 2 thuốc $(35,7 \%)$, phác đồ 3 thuốc $(13,2 \%)$, phác đồ 4 thuốc $(1,6 \%)$ và ít nhất là phác đồ 5 thuốc $(3,3 \%)$.

Bảng 3.6. Tỷ lệ các thuốc hạ glucose máu xuất hiện trong các phác đồ

\begin{tabular}{|l|c|c|}
\hline \multicolumn{1}{|c|}{ Thuốc hạ glucose máu } & Số bệnh nhân (n=182) & Tỷ lệ \% \\
\hline Metformin & 126 & 69,2 \\
\hline SGLT2-i & 27 & 14,3 \\
\hline DPP4-i & 51 & 28,0 \\
\hline Acarbose & 0 & 0,0 \\
\hline Sulfonylurea (SU) & 20 & 10,9 \\
\hline Insulin & 80 & 43,9 \\
\hline
\end{tabular}

Nhân xét: Tỷ lệ sử dụng metformin trong các phác đồ là cao nhất chiếm $69,2 \%$ tiếp theo lần lượt là insulin 43,9\%, thuốc ức chế DPP4 $28 \%$, ức chế SGLT2 14,3\% và SU 10,9\%. Ngoài ra không có bệnh nhân nào được sử dụng Acarbose.

Bảng 3.7. Phác đồ 1 thuốc hạ glucose máu

\begin{tabular}{|l|c|c|c|}
\hline \multicolumn{1}{|c|}{ Các phác đồ đơn trị } & Số bệnh nhân & $\begin{array}{c}\text { Tỷ lệ trong nhóm } \\
\text { phác đồ } \mathbf{( \% )}\end{array}$ & $\begin{array}{c}\text { Tỷ lệ trong toàn bộ } \\
\text { BN có dùng thuốc } \\
\text { hạ glucose máu (\%) }\end{array}$ \\
\hline Metformin & 34 & 85,0 & 18,7 \\
\hline DPP4-i & 3 & 7,5 & 1,6 \\
\hline SGLT2-i & 2 & 5,0 & 1,1 \\
\hline SU & 1 & 2,5 & 0,5 \\
\hline \multicolumn{1}{|c|}{ Tổng } & $\mathbf{9 0}$ & $\mathbf{1 0 0 , 0}$ & $\mathbf{4 9 , 5}$ \\
\hline
\end{tabular}


Nhận xét: Trong phác đồ 1 thuốc uống hạ glucose máu, metformin chiếm hầu hết các trường hợp với tỷ lệ 85,5\%, tiếp theo lần lượt là ức chế DPP4 (7,5\%), ức chế SGLT2 (5,0\%), Sulfonylurea (SU) chiếm tỷ lệ thấp nhất, $2,5 \%$.

Bảng 3.8. Các phác đồ kết hợp thuốc uống hạ glucose máu

\begin{tabular}{|c|c|c|c|}
\hline Các phác đồ đơn trị & $\begin{array}{l}\text { Số bệnh } \\
\text { nhânn }\end{array}$ & $\begin{array}{c}\text { Tỷ lệ trong } \\
\text { nhóm phác đồ } \\
\text { (\%) }\end{array}$ & $\begin{array}{l}\text { Tỷ lệ trong toàn bộ } \\
\text { BN có dùng thuốc hạ } \\
\text { glucose máu }(\%)\end{array}$ \\
\hline Metformin + DPP4-i & 26 & 41,9 & 14,44 \\
\hline Metformin + SGLT2-i & 14 & 22,6 & 7,78 \\
\hline Metformin + SU & 8 & 12,9 & 4,44 \\
\hline Metformin +SU+DPP4-i & 5 & 8,1 & 2,78 \\
\hline Metformin+SGLT2-i + DPP4-i & 5 & 8,1 & 2,78 \\
\hline Metformin+SGLT2-i + SU & 2 & 3,2 & 1,11 \\
\hline Metformin+SGLT2i+DPP4i+SU & 2 & 3,2 & 1,11 \\
\hline $\begin{array}{c}\text { Tổng } \\
\end{array}$ & 62 & $\mathbf{1 0 0 , 0}$ & 36,11 \\
\hline
\end{tabular}

Nhận xét: Có 3 phác đồ kết hợp 2 thuốc uống, 3 phác đồ kết hợp 3 thuốc uống và 1 phác đồ kết hợp 4 thuốc uống. Trongđó phối hợp metformin với ức chế DPP4 chiếm tỷ lệ cao nhất là $41,9 \%$, tiếp theo là phối hợp metformin với ức chế SGLT2 (22,6\%), metformin phối hợp SU $(12,9 \%)$. Các kết hợp 3 thuốc uống có tỷ lệ thấp $(3,2-8,1 \%)$ và chỉ có $2(3,2 \%)$ trường hợp phối hợp 4 thuốc uống.

Bảng 3.9. Các phác đồ có insulin

\begin{tabular}{|l|c|c|c|}
\hline \multicolumn{1}{|c|}{ Các phác đồ đơn trị } & $\begin{array}{c}\text { Số bệnh } \\
\text { nhần }\end{array}$ & $\begin{array}{c}\text { Tỷ lệ trong } \\
\text { nhóm phác đồ } \\
\mathbf{( \% )}\end{array}$ & $\begin{array}{c}\text { Tỷ lệ trong toàn bộ } \\
\text { BN có dùng thuốc hạ } \\
\text { glucose máu (\%) }\end{array}$ \\
\hline Insulin & 50 & 62,5 & 27,5 \\
\hline Metformin + Insulin & 17 & 21,3 & 9,44 \\
\hline Metformin+ DPP4-i + Insulin & 9 & 11,3 & 5,00 \\
\hline Metformin+ SGLT2-i + Insulin & 2 & 2,5 & 1,11 \\
\hline Metformin+SU+ Insulin & 1 & 1,3 & 0,56 \\
\hline Metformin+SGLT2i+DPP4i+Insulin & 1 & 1,3 & 0,56 \\
\hline Tổng & $\mathbf{8 0}$ & & $\mathbf{1 3 , 3 3}$ \\
\hline
\end{tabular}

Nhận xét: Có 5 phác đồ có dùng insulin, trong đó insulin đơn trị chiếm đa số là $62,5 \%$, thứ 2 là insulin phối hợp metformin $(21,3 \%)$ và phối hợp insulin với 2 thuốc metformin và ức chế DPP4 $(11,3 \%)$. Các phối hợp insulin với các thuốc uống hạ glucose máu khác chiếm tỷ lệ thấp $(1,3-$ $2,5 \%)$.

Bảng 3.10. Phác đồ thuốc hạ glucose máu theo mức HbAlc

\begin{tabular}{|c|c|c|c|c|}
\hline \multirow{2}{*}{ HbA1c (\%) } & \multicolumn{2}{|c|}{ Phác đồ thuốc hạ glucose máu (số lượng, tỷ lệ\%) } & \multirow{2}{*}{ Chung } \\
\cline { 2 - 4 } & $\begin{array}{c}\text { Đơn trị thuốc } \\
\text { uống }\end{array}$ & $\begin{array}{c}\text { Kết hợp thuốc } \\
\text { uống }\end{array}$ & $\begin{array}{c}\text { Insulin } \\
\text { (đơn trị/kết hợp } \\
\text { thuốc uống) }\end{array}$ & \\
\hline$<7,0$ & $23(88,5)$ & $3(11,5)$ & $0(0,0)$ & 26 \\
\hline $7,0-<8,5$ & $16(32,0)$ & $31(62,0)$ & $3(6,0)$ & 50 \\
\hline $8,5-<10,0$ & $1(3,5)$ & $19(65,5)$ & $9(31,0)$ & 29 \\
\hline$\geq 10,0$ & $0(0,0)$ & $25(32,5)$ & $52(66,5)$ & 78 \\
\hline Tổng & $40(22,0)$ & $78(42,9)$ & $64(35,2)$ & 182 \\
\hline
\end{tabular}


Nhận xét: Ở nhóm bệnh nhân có $\mathrm{HbA} 1 \mathrm{c}<$ $7 \%$, hầu hết được chỉ định 1 thuốc hạ glucose máu, một tỷ lệ nhỏ được chỉ định 2 thuốc uống và không có bệnh nhân nào được chỉ định insulin. Ở nhóm bệnh nhân có HbA1c từ $7-$ dưới $8,5 \%$, gần $2 / 3$ được dùng kết hợp thuốc uống và khoảng $1 / 3$ được chỉ định thuốc uống kết hợp và có tỷ lệ nhỏ được chỉ định insulin. Ở nhóm bệnh nhân có $\mathrm{HbA} 1 \mathrm{c}$ từ $8,5 \%$ đến dưới $10 \%, 2 / 3$ được chỉ định thuốc uống kết hợp và khoảng $1 / 3$ được chỉ định insulin.Ở nhóm bệnh nhân có $\mathrm{HbA} 1 \mathrm{c}$ từ $10 \%$ trở lên, $2 / 3$ được chỉ định insulin và khoảng $1 / 3$ được chỉ định thuốc uống kết hợp và không có bệnh nhân nào dùng thuốc uống đơn trị.

\section{BÀN LUẦN}

4.1. Đặc điểm của bệnh nhân nghiên cứu

Nghiên cứu cho thấy tuổi trung bình mới chẩn đoán ĐTĐ typ 2 là $51,7 \pm 11,7$ tuổi, cũng tương đồng với nghiên cứu của Nguyễn Vũ Quỳnh Thi và cộng sự tuổi trung bình là 51,35 $\pm 12,77$ tuổi [4]. Tỷ lệ nam có xu hướng nhiều hơn nữ, số tuổi mới phát hiện lần đầu cũng có xu hướng trẻ hơn.

Tỷ lệ bệnh nhân nhận thấy các bệnh nhân có tỷ lệ cao các bệnh lý liên quan đến ĐTĐ những yếu tố nguy cơ biến chứng ĐTĐ: $51,5 \%$ có thừa cân/béo phì, $47,1 \%$ rối loạn lipid máu - tương đương với tần suất của trong nghiên cứu của Huanhuan Zhou và cộng sự là 36,2 \% [5], và $26.5 \%$ có tăng huyết áp.

Về tình trạng khi chẩn đoán ĐTĐ, tỷ lệ bệnh nhân có tình trạng glucose máu cao chiếm tỷ khá cao, với $48 \%$ có triệu chứng lâm sàng của tăng glucose máu, $48,1 \%$ bệnh nhân có glucose máu lúc đói $>10 \mathrm{mmol} / \mathrm{L}, 15,7 \%$ có mức trên 16,7 mmol/L; $38,1 \%$ bệnh nhân có mức $\mathrm{HbA} 1 \mathrm{c}>10 \%$. Như vậy tình trạng chẩn đoán muộn ĐTĐ típ 2 vẫn hiện tượng phổ biến.

4.2. Thực trạng sử dụng thuốc điều trị ĐTÐ mới phát hiện tại bệnh viện Nội tiết Trung ương

Trong các phác đồ điều trị tại viện, metformin luôn được ưu tiên lựa chọn hàng đầu, chiếm hầu hết trong các phác đồ đơn trị (85\%), ở tất cả các phác đồ có kết hợp thuốc uống cũng như các phác đồ có kết hợp với insuilin. Điều này phù hợp với các khuyến cáo của Hội ĐTĐ Mỹ ADA 2019 [6], Hội các nhà nội tiết lâm sàng Mỹ (AACE) 2019 [1], Bộ Y tế 2017 [7], và cũng tương đồng như các nghiên cứu của [8] và [9] theo xu hướng dùng thuốc trên thế giới, trong đó metformin là thuốc lực chọn đầu tiên ở bệnh nhân ĐTĐ típ 2 mới chẩn đoán và tiếp tục duy trì sau đó nếu không có chống chỉ định. Tuy nhiên, một số trường hợp đợn trị với thuốc uống khác metformin được chỉ định, chiếm $15 \%$ trường hợp. Điều này có thể do bác sỹ cân nhắc như tăng glucose máu sau ăn ưu thế (ức chế DPP4) hoặc bệnh nhân thừa cân/béo phì (ức chế SGLT2). Mặt khác, các thuốc uống hạ glucose máu là ức chế DPP4 và ức chế SGLT2 đã được sử dụng ở một tỷ lệ đáng kể bệnh nhân, chiếm lần lượt 28,8 và $14,3 \%$ (kể cả đơn trị và kết hợp). Mặc dù có chi phí cao, nhưng nhờ có những ưu thế, được bảo hiểm y tế chi trả, các thuốc này đã được chỉ định nhiều hơn rõ rệt so với so với thuốc kinh điển thế hệ cũ là $S U$, chỉ được chỉ định ở 10,9\% bệnh nhân.

Việc chỉ định, lựa chọn phác đồ thuốc hạ glucose máu ở bệnh nhân ĐTĐ típ 2 có sự khác biệt rõ rệt theo tình trạng tăng glucose máu được đánh giá theo chỉ số HbA1c.

Đối với bệnh nhân có HbA1c <7\%, hầu hết được chỉ định thuốc uống đơn trị $(88,5 \%)$. Tuy nhiên vẫn còn một tỷ lệ nhỏ bệnh nhân được chỉ định kết hợp thuốc uống hạ glucose máu $(11,2 \%)$. Điều này là điều trị quá tích cực theo các khuyến cáo hiện nay và có thể là do tác động của nghiên cứu gần đây về hiệu quả kết hợp sớm thuốc uống hạ glucose máu kể cả ở bệnh nhân ĐTD có mức HbA1c < 7\%. Tuy nhiên chỉ nên lựa chọn này cho những bệnh nhân trẻ tuổi, chưa có biến chứng ĐTĐ hoặc bệnh nặng kèm theo, đồng thời cần hướng dẫn bệnh nhân phòng tránh, nhận biết và xử lý hạ glucose máu. Xu hướng điều trị tích cực cũng thể hiện rõ ở mức $\mathrm{HbA} 1 \mathrm{c}$ từ 7,5 đến dưới $10 \%$. Ở mức $\mathrm{HbA1c}$ từ 7,0 đến dưới $8,5 \%$ khuyến cáo của $\mathrm{ADA}$ là dùng đơn trị, thường là thuốc uống hạ glucose máu. Tuy nhiên trong nghiên cứu này chỉ có dưới $1 / 3$ được chỉ định đơn trị thuốc uống, ngược lại có gần $2 / 3$ được chỉ định kết hợp 2 thuốc hạ glucose máu. Tương tự, ở 
mức HbA1c 8,5 đến dưới 10\%, khuyến cáo của ADA là kết hợp 2 thuốc hạ glucose máu. Tuy nhiên trong nghiên cứu này, có $2 / 3$ bệnh nhân với mức $\mathrm{HbA} 1 \mathrm{c}$ này được chỉ định kết thuốc hợp thuốc uống, tuy nhiên đã có khoảng 1/3 bệnh nhân được chỉ định insulin, thuốc có hiệu quả hạ glucose máu cao nhất trong các thuốc uống hạ glucose máu. Cần cân nhắc nguy cơ hạ glucose máu khi điều trị tích cực bằng thuốc uống hạ glucose máu, tránh điều trị tích cực ở bệnh nhân có nguy cơ cao hạ glucose máu như tuổi cao, mắc bệnh nặng kèm theo. Đồng thời việc giáo dục bệnh nhân phòng tránh hạ glucose máu là rất cần thiết khi điều trị hạ glucose máu tích cực.

Mặt khác, ở mức $\mathrm{HbA} 1 \mathrm{c}$ từ $10 \%$ trở lên, theo khuyến cáo nên điều trị insulin tích cực. Tuy nhiên ở mức $\mathrm{HbA} 1 \mathrm{c}$ này việc điều trị chưa được tích cực ở tất cả các bệnh nhân như khuyến cáo. Chỉ có khoảng $2 / 3$ được điều trị insulin, còn lại khoảng $1 / 3$ được chỉ định thuốc uống kết hợp. Những lý do của tình trạng này có thể là sự từ chối của người bệnh, bệnh nhân điều trị ngoại trú, sự thận trọng của bác sỹ. Tuy nhiên, cần hạn chế tối đa tình trạng này. Việc điều trị insulin ở những bệnh nhân có triệu chứng lâm sàng của tăng glucose máu, mức glucose máu và $\mathrm{HbA} 1 \mathrm{c}$ quá cao là cần thiết để khôi phục tình trạng chuyển hóa glucose, đồng thời giúp phục hồi và duy trì chức năng tế bào beta lâu dài.

\section{KẾT LUẦN}

Ở bệnh nhân ĐTĐ típ 2 mới được chẩn đoán tại Bệnh viện Nội tiết Trung ương, metformin là thuốc được sử dụng ở hầu hết bệnh nhân, cả đơn trị và kết hợp. Các thuốc uống hạ glucose máu thế hệ mới cũng được sử dụng ở môt tỷ lệ đáng kể bệnh nhân, nhiều hơn so với sulfonylurea. Phần lớn chỉ định các phác đồ thuốc hạ glucose máu tuân theo các khuyến cáo chung hiện nay. Tuy nhiên, có tình trạng điều trị kiểm soát glucose máu tích cực hơn ở bệnh nhân có tình trạng gluose máu tăng mức nhẹ đến trung bình và ngược lại có tình trạng điều trị thiếu tích cực ở bệnh nhân có tình trạng glucose máu rất cao.

\section{TÀI LIÊUU THAM KHẢO}

1. K. C. J. Yuen et al., "American association of clinical endocrinologists and american college of endocrinology guidelines for management of growth hormone deficiency in adults and patients transitioning from pediatric to adult care", Endocr. Pract. Off. J. Am. Coll. Endocrinol. Am. Assoc. Clin. Endocrinol., vol. 25, no. 11, pp. 1191-1232, Nov. 2019, doi: 10.4158/GL-2019-0405.

2. Hội Tim mạch học Việt Nam (2020), "Chẩn đoán tăng huyết áp", http://vnha.org.vn/detail.asp?id=251 (accessed Sep. 28, 2020).

3. Hội Tim mạch học Việt Nam (2020), "Điều trị rối loạn Lipid máu ở một số nhóm bệnh nhân", http://vnha.org.vn/detail.asp?id=232 (accessed Sep. 28, 2020).

4. Hội Nội Tiêt và Đái Tháo Đường Việt Nam (2020), "Nghiên cứu tình trạng tiền ĐTĐ chưa được chẩn đoán", https://vade.org.vn/modules.php?name= News\&op=viewst\&sid=162 (accessed Sep. 25, 2020).

5. H. Zhou, C. Zhang, J. Ni, and X. Han, "Prevalence of cardiovascular risk factors in non-menopausal and postmenopausal inpatients with type 2 diabetes mellitus in China," BMC Endocr. Disord., vol. 19, no. 1, p. 98, Oct. 2019, doi: 10.1186/s12902-019-0427-7.

6. A. D. Association, "1. Improving Care and Promoting Health in Populations: Standards of Medical Care in Diabetes2019," Diabetes Care, vol. 42, no. Supplement 1, pp. S7-S12, Jan. 2019, doi: 10.2337/dc19-S001.

7. I. team, "Quyết định số 3319/QĐ-BYT ngày 19/7/2017 về việc ban hanh tài liệu chuyên môn 'Hướng dẫn chẩn đoán và điều trị đái tháo đường tip 2," Cuc quản lý khám chũa bệnh. https://kcb.vn/vanban/quyet-dinh-so3319qd-byt-ngay-1972017-ve-viec-banhanh-tai-lieu-chuyen-mon-huong-dan- 
chan-doan-va-dieu-tri-dai-thao-duongtip-2 (accessed Jun. 18, 2019).

8. C. Wang, Y. Gao, L. Zhu, M. Huang, Y. $\mathrm{Wu}$, and J. Xuan, "Treatment Patterns in Patients With Newly Diagnosed Type 2 Diabetes in China: A Retrospective, Longitudinal Database Study," Clin. Ther., vol. 41, no. 8, pp. 1440-1452, 2019, doi: 10.1016/j.clinthera.2019.05.003.
9. Y. Z. Tan et al., "Trends in medication utilization, glycemic control and outcomes among type 2 diabetes patients in a tertiary referral center in Singapore from 2007 to 2017," J. Diabetes, vol. 11, no. 7, pp. 573-581, Jul. 2019, doi: 10.1111/1753-0407.12886. 